\title{
CONSTRUCTIVISMO Y APRENDIZAJE DE UN IDIOMA EXTRANJERO
}

\section{Maurizia D'Antoni}

La institución que llamamos "escuela" constituye una de las fuentes de transmisión de cultura dentro de la sociedad; por su carácter inherente al desarrollo social percibimos su existencia y su conformación como naturales lo que nos dificulta la reflexión cuidadosa, acerca de su culturalidad.

Para entender el proceso de enseñanza y aprendizaje de un idioma extranjero requiere del apoyo de dos posturas tradicionales en el amplio marco constructivista: La vertiente biológica, que se preocupa de señalar las raíces neurológicas y el procesamiento de la información lingüística o la vertiente social, más concentrada en el esclarecimiento de los roles alumno-docente, de los docentes, de la institución en la enseñanza. (Klinger y Vadillo, 2000). 
La escuela es la institución que promueve, de manera organizada y consciente, el desarrollo intelectual de los alumnos y la actividad mental constructiva, según Solé y Coll, 1993 además e impulsa la formación de personas únicas e irrepetibles en un contexto social determinado.

La escuela es, para los alumnos, el medio que les facilita la comprensión de la realidad social, al proponerles conocimientos y modalidades para su adquisición, además la escuela tiene como tarea la socialización en el sentido amplio, entendiéndolo no sólo como la capacidad de funcionar en un grupo sino también como la construcción del sentido moral, del desarrollo de habilidades más o menos reconocidas y aprobadas socialmente.

La construcción del conocimiento posibilita un sujeto activo que construye su mundo: al hacerlo, sin embargo, el sujeto no está solo. Los demás son parte imprescindible en ese proceso para que los conocimientos tengan sentido en un universo compartido, en el que sobrevivir está relacionado con el conocimiento así como con la comunicación.

Miras (1993), nos advierte que los alumnos poseen cierta cantidad de esquemas, es decir que no son portadores de un conocimiento global de la realidad, tienen un conocimiento de aquellos aspectos de la realidad con los cuales han podido entrar en contacto a lo largo de su vida. Lo anterior implica una visión activa del conocimiento como en parte construido de recursos personales de base (hasta genéticos), pero también activado por la exposición de los sujetos a diferentes aspectos de la realidad.

Los esquemas que se poseen, además no son válidos únicamente por la cantidad de informaciones que contengan, 
igualmente importante es su grado de organización interna: organización y coherencia interna prueban ser características claves al examinar la calidad de la situación de aprendizaje.

Los esquemas de conocimiento, a la vez, pueden ser amplios y bien organizados pero más o menos adecuados a la realidad en la que la persona se desenvuelve.

La definición de cuán adecuado o menos es el conocimiento es relativamente fácil cuando se trata de conocimientos de tipo científico. Cuando no sea así, la definición requiere tomar en cuenta actitudes, valores y normas sociales, lo que implicará una amplia complejidad valorativa.

Los profesores se apropian de una visión, de un pensamiento pedagógico. Tal sistema de pensamiento es el instrumento que les sirve para procesar la información presente en la situación educativa así como adecuarla a las metas que se pretenden.

Como cualquier otro profesional, el docente reflexiona acerca de su quehacer, de la acción educativa y el por qué de ella. Necesariamente debe recurrir a referentes que lo guíen en el proceso. Requieren del manejo teórico que le permita interpretar, analizar y finalmente intervenir sobre la realidad e integrar un pensamiento estratégico. Las teorías le permiten al docente contextualizar y priorizar metas y finalidades de su actividad. Si bien el docente, como protagonista de la enseñanza, participa en una actividad profundamente interactiva, no siempre se le toma en cuenta, considera y estudia en tanto objeto de tal interacción: como el alumno, el profesor también lleva en el proceso de enseñanza-aprendizaje sus teorías previas a la enseñanza, creencias, inclusive acerca de su misma disciplina, sin embargo, 
no siempre es considerado portador de teorías coherentes y estructuradas.

\section{De una escuela de idiomas}

Una Escuela privada que imparte lecciones de italiano, principalmente en las tardes y en las noches, no constituye el tipo de escuela, objeto de estudio frecuente para analizar el proceso de enseñanza y aprendizaje. Esto por cuanto su propósito no es la socialización de los sujetos, más bien y los conocimientos que allí se adquieren representan para las personas un complemento de su formación.

Los alumnos de una escuela como la que se considera aquí son personas que comparten cierto nivel de formación, son personas adolescentes o adultas escolarizadas, que están en proceso de terminar o han terminado su educación básica, muy a menudo su educación superior.

Una escuela de idiomas, por lo tanto, probablemente no tenga tantas responsabilidades en la formación de los alumnos, en tanto que la responsabilidad del docente para con el aprendizaje se especializa, ya que no existe una habilidad general para hacer pensar bien. Más bien, según Carretero (1987) enseñarles bien a los alumnos cobra diferentes formas según las distintas disciplinas. La pericia que a lo largo de la práctica profesional el docente adquiere tendrá por lo tanto su dirección específica, relativa a la especialidad del profesor.

El concepto de pericia sirve para definir el conjunto de habilidades que el docente integra con la experiencia y sabe expresar. Eero Ropo (En Carretero, 1987) ofrece un breve discurso histórico del concepto de pericia en la enseñanza y la 
conceptualiza como basada en estructuras cognitivas bien desarrolladas que permiten una conducta eficiente de los docentes en las interacciones educativas (pág. 101).

Interesa, por lo tanto, destacar aspectos específicos ligados al contexto de la pericia en la enseñanza de los idiomas.

Uno de los aspectos de interés, al examinar la enseñanza y el aprendizaje en una escuela de italiano, en América latina, es su función de puente entre la cultura costarricense y la cultura italiana en el momento histórico actual de la globalización, que implica la existencia de grandes masas migratorias en el mundo. La importancia del trabajo relativo a la confrontación con la cultura italiana de los estudiantes del idioma estriba no solamente en la posible migración de éstos a Italia: se piensa que reflexionar sobre otro idioma producto de otra cultura debe de tener efectos sobre la construcción de la realidad de la persona y por lo tanto, sobre sus ideas relativas al otro y a la otredad.

Hay que aclarar que la Escuela en objeto se propone como una institución italiana en tierra extranjera, ligada a la madre patria y donde el cuerpo enseñante es italiano.

Para sentir interés por lo que se estudia hay que saber lo que se pretende. Más aún: existe una intención con la que el alumno se enfrenta a la tarea del aprendizaje (Solé, 1993). Tal intención contiene elementos inconscientes entre los cuales es probable que juegue un papel de la representación del mundo lingüístico al que se acercan los discípulos y el país que lo expresó, al igual que la posición propia -cómo ésta es percibida - con respecto al extranjero. 


\section{Discusión}

Interesa considerar si existe transmisión de cultura y por lo tanto una acción orientada ideológicamente, en una escuela de italiano situada en América Latina, cuya finalidad, modesta si se compara con los alcances de la educación formal, es la de enseñarles a personas generalmente escolarizadas un idioma extranjero más.

El discurso involucra a los usuarios de la institución y a sus motivaciones para acercarse al aprendizaje del italiano. La composición social del alumnado y el significado socialmente atribuido a la frecuencia de un curso de idiomas son fenómenos a considerarse.

Es probable que el estudio privado del inglés implique por parte del alumno costarricense situarse en una visión del mundo, tomar una posición: no es un secreto la condición de dependencia política y económica de Costa Rica de los Estados Unidos, el hecho de que probablemente cada costarricense conozca al menos a un compatriota que vive en el estado del Norte y fantasee, piense o sepa de negocios, turismo, becas de estudio, para sí o sus allegados.

Igualmente probable resulta la identificación del inglés como lengua de estudio, con los Estados Unidos como referente único de tal actividad excluyendo como referentes, por ejemplo, Irlanda, Nueva Zelanda o el inglés como lengua franca para comunicarse en el mundo.

El italiano se estudia, según los estudiantes, como "tercera" lengua, como idioma no tan necesario para el desarrollo profesional; por ser el idioma de los antepasados que vinieron a Costa Rica; por ser un idioma percibido como bonito, 
musical, fácil. Los estudiantes, una y otra vez, refieren: "Estudio italiano por que siempre me ha gustado". Suena como un sueño pero se percibe una forma de resistencia, dentro del sueño.

El idioma italiano como "tercer idioma" resulta inevitablemente contrapuesto al primero, el idioma materno y al segundo, el inevitable idioma de la neocolonización, el que se tiene que estudiar pero no gusta tanto o se da por sentado que hay que conocer para tener posibilidades profesionales. Aparece el italiano casi como una forma de protesta, un intento a veces de identificarse con ancestros europeos, contraponiéndole a la potencia del Norte una de origen europea, vista como más "fuerte" que la autóctona.

Si las personas llegan con expectativas más o menos conscientes como las que se mencionan, entonces el encuentro efectivo con el idioma, con sus dificultades y con la cultura italiana puede desencadenar una crisis.

Las informaciones que no se asimilan a lo ya existente, sean estas informaciones de origen gramatical o informaciones relativas a la cultura y a la organización social son desechadas. Puede darse entonces el rechazo de la información nueva o la integración de todo lo que sea posible a los esquemas activos en el estudiante.

A partir de lo anterior, sería interesante plantear una investigación sobre la frecuencia y repetición de algunos errores típicos del costarricense que aprende el italiano.

Las condiciones previas de acercamiento al idioma italiano son seguramente el conocimiento del idioma materno, el español americano, que tiene similitud con el neolatino 
italiano, o el conocimiento de otros idiomas extranjeros: el francés entre todos por el parentesco entre las estructuras sintácticas de francés e italiano y a la vez por la aproximación a otra cultura que el estudiante debe haber emprendido a través del estudio previo de una lengua extranjera.

En cuanto al grado de integración de los esquemas de conocimiento, se considera que los conocimientos previos de otros idiomas juegan un papel positivo en el aprendizaje del italiano si los mismos presentan un alto grado de organización y coherencia. (Solé, 1993).

El profesor, mediador cultural en la situación presentada, cumple una doble función: como portador de un pensamiento psicopedagógico que inscribe su actividad en un por qué y un para qué con vertientes ideológicas y se presenta ante sus alumnos con interpretaciones y análisis del proceso enseñanza-aprendizaje.

Además, el profesor es mediador entre el estudiante y el texto de estudio que es portador de una imagen de Italia así como de una imagen del usuario-tipo del texto. Un tercer factor es la Escuela, dirigida por personas portadoras también de ideas acerca de la función de la enseñanza, quienes deciden tamaño y número de grupos, distribución de materiales por nivel de estudios, número de horas por sesión semanales, horarios, recesos, existencia y frecuencia de actividades de evaluación, confección de las evaluaciones, criterios de calificación, costo de los cursos y otros aspectos.

El docente es quien se hace intérprete ante los alumnos de las intenciones presentes en la Escuela y en el método, haciendo explícitos los contenidos lingüísticos, gramaticales, culturales en el aula, interpretando para los alumnos 
las intenciones didácticas expresadas de manera diferente por la Escuela y por el método de estudio. El docente comenta y ubica los contenidos de carácter cultural del texto y los vincula con las estructuras lingüísticas o las diferencias gramaticales entre el italiano y el castellano, apoyándose en aspectos históricos y culturales.

Para los usuarios el proceso de aprendizaje consistirá en aprender a hablar italiano a partir de una serie de ideas, prejuicios, imágenes, vivencias, fragmentos de conocimientos acerca de Italia y del italiano con un grupo de costarricenses que la compartirán, en parte. Moscovici (1994) define las representaciones sociales como el conjunto de ideas, prejuicios, teorías ingenuas y creencias compartidas por un grupo social acerca de un tema. Tales representaciones se encontrarán con las que el/la docente lleva consigo, recordando que el docente es el puente entre alumno-institución y el método de estudio.

\section{Conclusiones}

El proceso de la globalización, con sus movimientos de masas por el planeta es un fenómeno con profundas implicaciones, que en parte todavía se nos escapan. Las personas llevan consigo su idioma, los idiomas viajan, no sabemos si a la misma velocidad de las migraciones por lo que es de sumo interés el tema de cómo varían las representaciones sociales de los grupos humanos y de los idiomas en el contexto de la globalización.

La cambiante representación de nuestro universo lingüístico y cultural en cuanto a profesores, influye en el proceso de enseñanza y aprendizaje de un idioma y pesa sobre la función de puentes que cumplimos, en este caso, entre las 
intenciones del método de estudio, las de la Institución donde desempeñamos nuestro trabajo y el estudiante.

Ser conscientes de tal tarea implica también conocer que las representaciones de las cuales somos portadores no constituyen siempre un conjunto estructurado y coherente, lo cual nos obliga a estar alerta.

No tenemos solamente una obligación hacia la actualización de nuestros conocimientos, la obligación está también en la observación crítica de los contenidos y de la transmisión cultural que hagamos, por cuenta propia o como trámites.

Si lo anterior es cierto se impone a la atención, una vez más, la necesidad de coherencia y trabajo conjunto de cuerpo docente y de la institución.

El alumno se enfrenta a la tarea de estudiar un idioma con conocimientos previos, con una intención en parte inconsciente, con una representación social de su universo cultural y del otro. En su proceso de construcción de significados, los estudiantes de italiano confrontan su representación del Italiano y de Italia con la que se les propone. Frente a ellos encuentran "puentes" y algunas contradicciones.

El italiano es visto como tercera opción, mediador entre dos: de un lado una identidad costarricense "débil" y el inglés, "fuerte" y presente, en lo cultural, lo político, lo imaginario, que se respeta y se rechaza.

Algunos estudiantes afirman haberse matriculado por ser de origen italiano y es muy común que todos se refieran a un mundo lingüístico que describen como fácil, amigable, acogedor. 


\section{BIBLIOGRAFIA}

1. Carretero, Mario (comp.). 1987. Procesos de enseñanza y aprendizaje. Edic. esp. Buenos Aires, Aique Grupo Editor.

2. Idem. 1997. Introducción a la psicología cognitiva. Buenos Aires, Aique Grupo Editor.

3. Katerinov, Katerin. 1993. Rassegna dei pricipali metodio per l'iunsegnamento delle lingue straniere. Perugia. Ediciones Guerra.

4. Klinger, Cynthia K. y Vadillo, Guadalupe B. 2000. Psicología cognitiva. Estrategias en la práctica docente. México. McGraw-Hill.

5. Moscovici, Serge (comp.). 1994. La relazione con l'altro. Trad. Ital. Milano. Raffaello Cortina Editore.

6. Ropo, Eero 1987. "Diferencias en la enseñanza de docentes de inglés, expertos y principiantes". En: Carretero, cit.

7. Solé, Isabel. 1993. "Disponibilidad para el aprendizaje y sentido del aprendizaje". En: Varios autores, El constructivismo en el aula. Barcelona. Editorial Graó.

8. Titone, Renzo. 1995. Problemas psicológicos en el aprendizaje de un segundo idioma. Perugia. Ediciones Guerra. 